\title{
Intranasal steroids decrease eosinophils but not mucin expression in nasal polyps
}

\author{
P-R. Burgel*, L.O. Cardell ${ }^{\#}$, I.F. Ueki ${ }^{\oplus}$, J.A. Nadel
}

Intranasal steroids decrease eosinophils but not mucin expression in nasal polyps. P-R. Burgel, L.O. Cardell, I.F. Ueki, J.A. Nadel. (C) ERS Journals Ltd 2004.

ABSTRACT: Increased mucin expression is a feature of nasal polyposis. Corticosteroids reduce polyp size and symptoms, but their effect on mucin production remains unknown. In this study, the effects of intranasal corticosteroids on MUC5AC mucin expression, nasal resistance, eosinophil and neutrophil infiltration, epidermal growth factor receptor (EGFR), interleukin (IL)-8, and tumour necrosis factor (TNF)- $\alpha$ expression was assessed in nasal polyps.

In nine subjects, one nasal polyp was removed surgically before treatment and another was removed after 8 weeks of intranasal fluticasone $\left(400 \mu \mathrm{g} \cdot \mathrm{day}^{-1}\right)$. Tissues were processed for in situ hybridisation and immunohistochemical staining. Described effects of fluticasone on nasal polyps (reduction in nasal resistance and in eosinophil infiltration) were evaluated. Morphometric analysis was performed to assess the effect of fluticasone on epithelial-, MUC5AC-, EGFR- and IL-8-stained areas, TNF- $\alpha$ stained cells, and neutrophil numbers.

Treatment with fluticasone decreased nasal resistance and intra-epithelial eosinophils. The MUC5AC-stained area in the epithelium was unchanged by treatment; MUC5AC mRNA expression was unaffected by treatment. EGFR-stained area, intraepithelial neutrophil numbers, IL-8 and TNF- $\alpha$ expression were also unchanged by therapy.

Intranasal fluticasone was effective in decreasing nasal airflow resistance and intraepithelial eosinophils but had no effect on mucin or epidermal growth factor receptor expression or on neutrophil recruitment.

Eur Respir J 2004; 24: 594-600.
*Service de Pneumologie, Université René Descartes, Hôpital Cochin, Paris, France. ${ }^{\#}$ Dept of Otorhinolaryngology, Malmö University Hospital, Malmö, Sweden. "Cardiovascular Research Institute, and Dept of Medicine and Physiology, University of California, San Francisco, CA, USA.

Correspondence: J.A. Nadel, Cardiovascular Research Institute, Box 0130, University of California San Francisco, San Francisco, CA 94 143-0130, USA.

Fax: 014154762283

E-mail: janadel@itsa.ucsf.edu

Keywords: Airway epithelium epidermal growth factor receptor interleukin-8

leukocyte recruitment mucous hypersecretion steroid treatment

Received: February 42004

Accepted after revision: May 42004

This work was funded by private funds. P-R Burgel is a recipient of a grant from "Collège des Professeurs de Pneumologie".
Goblet cell hyperplasia and increased mucin expression are features of nasal polyp epithelium [1], but, currently, no effective therapy for mucus hypersecretion is established. Eosinophil infiltration is a characteristic finding in nasal polyp tissue. Neutrophils are recruited into the airways in hypersecretory airway diseases (e.g. chronic obstructive pulmonary disease, cystic fibrosis, bronchiectasis, acute asthma) and are also found in nasal polyps [2]. Neutrophil chemoattractants are upregulated in the airways of these diseases [3] and expression of the neutrophil chemoattractant interleukin (IL)-8 is reported in nasal polyp tissue [4]. Several neutrophil products are reported to play important roles in mucin production, including oxygen free radicals [5] and elastase [6]. Eosinophil products also increase mucin production in airway epithelial cells [7]. Therefore, both eosinophils and neutrophils have been suspected to play roles in the increased mucin expression found in nasal polyps [1].

Corticosteroids are the recommended medical therapy for nasal polyps. They are effective in decreasing the size of polyps [8,9] and in inhibiting eosinophil infiltration into polyp tissue [10], but their effect on mucin production is not established.

Several mucins are expressed in human airways. Among these mucins, gel-forming mucins found in airway secretions include MUC2, MUC5AC and MUC5B. MUC2 expression has not been found consistently in immunohistochemical studies [11] and only a small amount of MUC2 protein has been found in airway secretions [12]. Although MUC5B is reported to be expressed in goblet cells in normal nasal epithelium, it is believed to be localised preferentially to airway submucosal glands [13]. Furthermore, there appear to be no reports of MUC5B protein expression in nasal polyps. In contrast, MUC5AC is consistently reported to be expressed in both nasal and lower airway epithelium [1, 11]. We have previously shown that MUC5AC gene and protein are expressed in nasal polyp epithelium, and that MUC5ACstained area in nasal polyp epithelium is comparable to $\mathrm{AB} /$ PAS-stained area [1]. Because both epidermal growth factor receptor (EGFR) activation [14] and leukocyte products have been implicated in mucin production, the effects of intranasal fluticasone on mucin MUC5AC and EGFR expression, and on leukocyte infiltration were examined in this study.

In each subject, one polyp was removed before corticosteroid therapy and a second polyp was removed after 8 weeks of treatment with an intranasal corticosteroid, fluticasone. The effectiveness of fluticasone on the size of polyps (evaluated by nasal airflow resistance) and eosinophil numbers was assessed, both of which are known to be decreased by fluticasone [10]. To assess the effect of fluticasone on mucin production and its effect on the EGFR cascade, in situ hybridisation and immunohistochemistry for MUC5AC gene, and protein expression and immunohistochemistry for EGFR protein 
were performed. Neutrophil infiltration, and expression of IL-8 and tumour necrosis factor (TNF)- $\alpha$ were also examined.

\section{Methods}

\section{Subjects}

Nasal polyps were removed from nine subjects with bilateral nasal polyposis requiring surgical intervention. Nasal polyposis was identified based on clinical symptoms (nasal obstruction, anosmia, sneezing, excessive secretions, itching) and based on the visualisation of polyps by anterior rhinoscopy. Individuals with the following were excluded: aspirin-induced airway symptoms, cystic fibrosis, ciliary dyskinesia, a history of concurrent purulent nasal infection during the 6 weeks before the study and nasal surgery during the past year. No subjects suffered from asthma that required continuous medication. Skin-prick tests were performed with a standard panel of 10 common airborne allergens (ALK, Copenhagen, Denmark) including pollen, house dust mites, mould and animal allergens. Six out of nine subjects had a positive skin test for at least one allergen. Although this study was not designed to examine differences between atopic and nonatopic subjects, no differences were observed between the two groups in neutrophil or eosinophil infiltration, as described previously [15]. EGFR and MUC5AC mucin expression were also similar in atopic and nonatopic subjects. Steroids were withheld for a minimum of 6 weeks prior to the study. After this run-in period, a polyp was removed surgically in each subject; no other surgical procedures were performed. Two weeks later, rhinomanometry was performed to measure nasal airflow resistance, and then therapy with intranasal fluticasone $(200 \mu \mathrm{g}$ twice daily) was initiated. This regimen was chosen based on the results of previous placebo-controlled studies showing positive effects of fluticasone on polyp symptoms, size and eosinophil infiltration $[8,10,16]$. Because these effects of steroids on polyps are well described, they were used as positive controls for efficacy of corticosteroid delivery. Therefore, as reported in a previous study [17], a placebo treatment group was not included. After 8 weeks of fluticasone therapy, measurement of nasal airflow resistance was repeated, and then another polyp was removed.

All studies were approved by the Ethics Committee of the University of Malmö (Malmö, Sweden) and an informed written consent was obtained from each subject.

\section{Rhinomanometry}

Nasal airflow resistance was determined for each nostril using active anterior rhinomanometry [18], a method where nasal airflow and pressure are measured at the nostrils during respiration. Before performing rhinomanometry, subjects rested in the sitting position. A pressure catheter was inserted in a nostril that was occluded with a strip of adhesive tape, and the other end was connected to a pressure transducer. Care was taken to insure that the sides of the catheter did not contact any part of the nasal mucosa. Flow was measured at a pressure of $1.5 \mathrm{cmH}_{2} \mathrm{O}$ with a pneumotachograph, via a mask held airtight over the nose and mouth by the subject with as little compression as possible. Nasal airflow resistance was expressed in $\mathrm{cmH}_{2} \mathrm{O} \cdot \mathrm{L}^{-1} \cdot \mathrm{s}^{-1}$.

\section{Tissue processing and immunohistochemistry}

Nasal polyps were removed surgically, fixed immediately in $10 \%$ formalin, embedded in paraffin and cut into $5-\mu \mathrm{m}$ sections. The sections were deparaffinised, rehydrated and treated with $0.3 \% \mathrm{H}_{2} \mathrm{O}_{2}$ in methyl alcohol. PBS containing $0.05 \%$ Tween-20 and $1 \%$ bovine serum albumin (BSA) was used as diluent for the following antibodies: a monoclonal antibody (mAb) to MUC5AC (clone 45M1; dilution 1:500; Neomarkers, Fremont, CA, USA); a mAb to EGFR (Ab-1; dilution 1:100; Calbiochem, La Jolla, CA, USA); a mAb to eosinophil cationic protein (EG2; dilution 1:1,000; Pharmacia Upjohn, Kalamazoo, MI, USA); a mAb to human neutrophil elastase (NP57; dilution 1:100; DAKO Corp., Carpinteria, CA, USA); a polyclonal Ab to IL-8 (dilution 1:20; Biosource, Camarillo, CA, USA); and a polyclonal rabbit anti-human antibody to TNF- $\alpha$ (dilution 1:1,000; Genzyme Corp, Cambridge, MA, USA).

Tissue sections were incubated with $2 \%$ BSA at room temperature for $1 \mathrm{~h}$ and were then incubated with primary antibody at room temperature for $2 \mathrm{~h}$. After removing excess $\mathrm{Ab}$ by washing with PBS, sections were incubated with a biotinylated horse anti-mouse Ab (dilution 1:200; Vector Laboratories, Burlingame, CA, USA) or with a biotinylated goat anti-rabbit Ab (dilution 1:200; Vector Laboratories) for $1 \mathrm{~h}$ at room temperature. Bound $\mathrm{Ab}$ was visualised according to standard protocols for avidin-biotin-peroxidase complex method (Elite ABC kit; Vector Laboratories). Tissue sections were counterstained with haematoxylin. Omission of the primary $\mathrm{Ab}$ and incubation with an irrelevant mouse immunoglobulin (Ig)G antibody (DAKO) were used as negative controls. Alcian Blue (AB)/PAS was performed for detection of mucous glycoconjugates.

\section{In situ hybridisation for MUC5AC $m R N A$}

MUC5AC gene expression was assessed by in situ hybridisation with ${ }^{35}$ S-labelled riboprobes. Preparation of the probes and in situ hybridisation were performed as described previously [19].

\section{Eosinophil and neutrophil numbers}

Quantification of eosinophil and neutrophil numbers in polyp tissues was performed by counting numbers of human neutrophil elastase (HNE)-stained (for neutrophils) and EG2stained (for eosinophils) cells in epithelium and subepithelium. Epithelium was defined as the area between cilia and basal membrane. Subepithelium was defined as the area immediately underneath the basal membrane (depth: one high power field at $400 \times=0.0125 \mathrm{~mm}$ ). For each layer (epithelium, subepithelium), 10 high-power fields (magnification $400 \times$ ) were selected randomly and positively stained cells were counted. Results are expressed as the number of cells per $\mathrm{mm}$ of basal membrane in epithelium and as the number of cells per $\mathrm{mm}^{2}$ in subepithelium.

\section{Epithelial, and MUC5AC- and EGFR-stained areas}

Measurements of epithelial, and MUC5AC- and EGFRstained areas in polyp epithelium were performed using a semi-automatic imaging system that included a microscope, a video camera and a computer. Because of the heterogeneity of polyp epithelium [1], for EGFR- and MUC5AC-stained areas, and total epithelial area, data were obtained from two randomly selected polyp sections in each subject. In each section, first images of all intact epithelium were recorded at $100 \times$ magnification. Next, epithelial area was measured on a computer screen using a grid composed of points; intersections of 
points with epithelium were counted and converted to areas (each point corresponding to a known area) [11]. Results obtained in two sections were averaged and expressed as $\mathrm{mm}^{2}$ of epithelium per $\mathrm{mm}$ of basal membrane. The median length of epithelium analysed in each section was $15.1 \mathrm{~mm}$ (range 4.4-23.3). Areas of epithelium occupied by MUC5AC- and by EGFR-stained cells were also measured by point counting using a grid (supra vide). Results obtained in two sections were averaged and were expressed as $\mathrm{mm}^{2}$ of MUC5AC or EGFR staining per mm of basal membrane. Results were not different when they were expressed as \% positively stained area of epithelium.

\section{IL-8-stained area}

Visualisation of staining for IL-8, a small diffusible molecule, required higher magnification than visualisation of MUC5AC and EGFR staining. Therefore, measurements were performed at $400 \times$ magnification: ten images of epithelium were randomly obtained, and areas of epithelium occupied by IL8-stained cells were measured by point counting using a grid (supra vide). Results were expressed as $\mathrm{mm}^{2}$ of IL-8 staining per mm of basal membrane.

\section{TNF- $\alpha$-stained cells}

As TNF- $\alpha$ in epithelium was expressed mostly in recruited inflammatory cells but also in epithelial cells (see Results section), this molecule was assessed by counting positively stained cells (both epithelial and inflammatory cells); for each polyp, 10 high-power fields (magnification $400 \times$ ) were selected randomly in a single section and positively stained cells were counted. Results are expressed as cells per mm of basal membrane.

\section{Statistics}

Data obtained from measurements of nasal airflow resistance and from morphometric measurements of epithelial area, MUC5AC-, EGFR- and IL-8-stained areas, and HNE-, EG2- and TNF- $\alpha$-stained cells before and after steroid treatment were compared using the nonparametric Wilcoxon signed-rank test. A p-value $<0.05$ for the null hypothesis was accepted as indicating a statistically significant difference. Sections were evaluated by a single observer on two different occasions in coded random order. All intra-observer coefficients of variation for repeated measurements were $<9 \%$.

\section{Results}

\section{Nasal airflow resistance}

Patients with nasal polyps had variable nasal airflow resistance before therapy. Intranasal fluticasone $(400 \mu \mathrm{g}$, daily for 8 weeks) decreased nasal airflow resistance significantly $(\mathrm{p}<0.05$, fig. 1).

\section{Eosinophil and neutrophil numbers}

Before therapy, eosinophils and neutrophils were present in polyp epithelium. Fluticasone decreased EG2-positive eosinophil numbers $(\mathrm{p}<0.01)$, but $\mathrm{HNE}$-positive neutrophil numbers were unaffected ( $\mathrm{p}=0.84$; fig. 2 ).

In the subepithelium of polyps, EG2-positive eosinophil

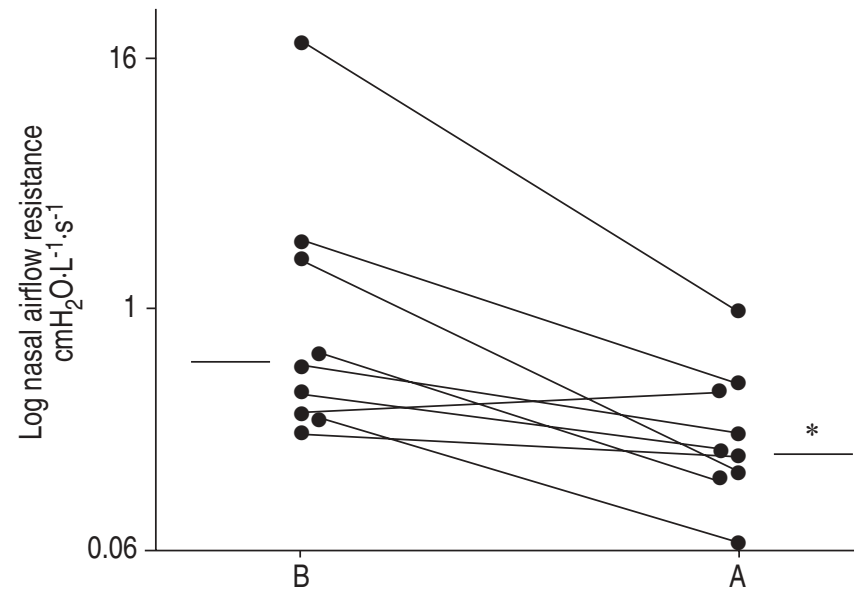

Fig. 1. - Nasal airflow resistance was measured by active anterior rhinomanometry in subjects before (B) and after (A) treatment with intranasal fluticasone. Fluticasone decreased airflow resistance $\left(^{*}\right.$ : $\mathrm{p}<0.05$ compared to before fluticasone). Connecting lines indicate data obtained in the same subject. Horizontal bars represent median values.
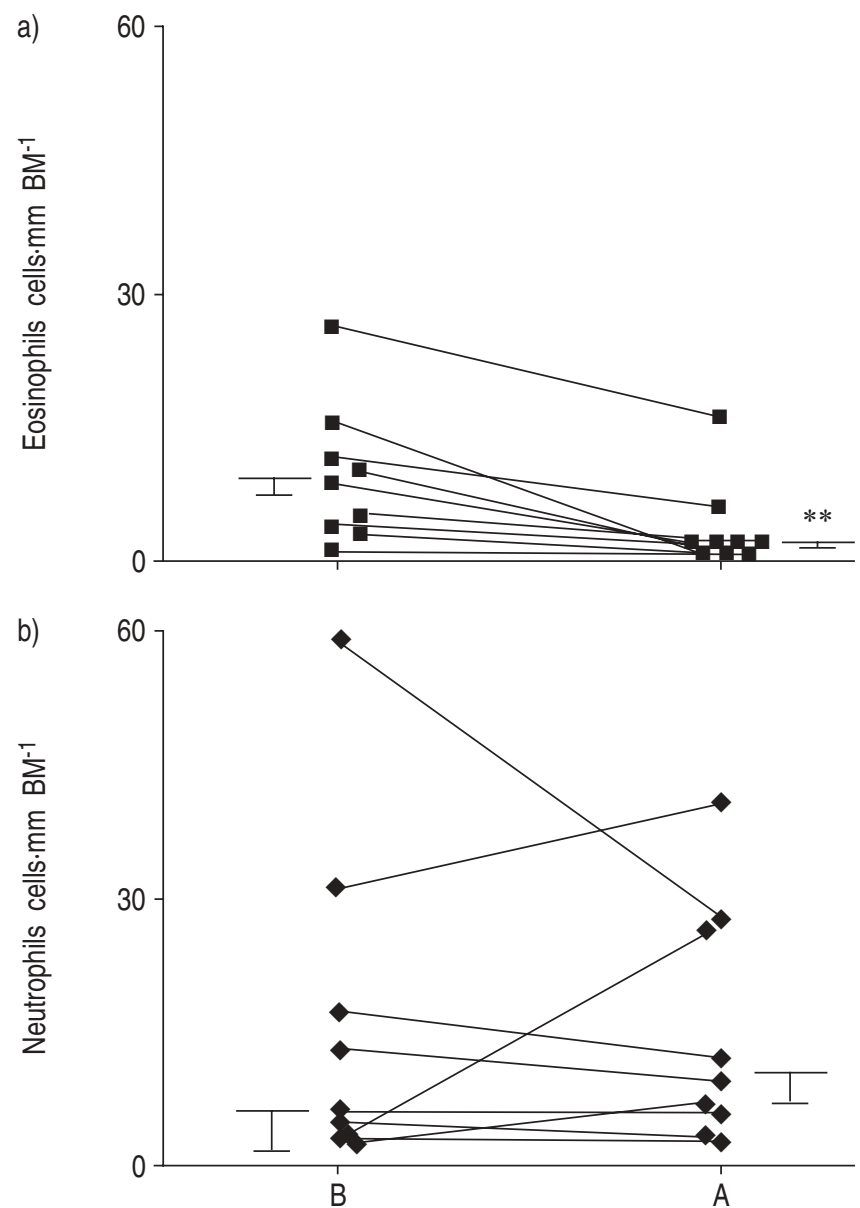

Fig. 2. - a) Eosinophils (assessed by EG2-stained cells) and b) neutrophils (assessed by human neutrophil elastase (HNE)-stained cells) were counted in polyp epithelium of subjects before (B) and after (A) fluticasone treatment. Fluticasone decreased intra-epithelial eosinophil $(* *: \mathrm{p}<0.01)$ but not intra-epithelial neutrophil numbers significantly $(\mathrm{p}=0.84)$. Data are presented as numbers of cells per $\mathrm{mm}$ of basal membrane (BM). Connecting lines indicate data obtained in the same subject. Horizontal bars represent median values. Vertical bars indicate SEM. 
numbers were also decreased by fluticasone (median 28 cells $\cdot \mathrm{mm}^{-2}$ (range 2-88) before treatment versus 6 cells $\cdot \mathrm{mm}^{-2}$ $(0-42)$ after treatment, $\mathrm{p}<0.01)$, whereas HNE-positive neutrophil numbers were unaffected $\left(24\right.$ cells $\cdot \mathrm{mm}^{-2}$ (1-94) before treatment versus 17 cells $\cdot \mathrm{mm}^{-2}(6-70)$ after treatment, $\mathrm{p}=0.65)$.

\section{Morphometric analysis of epithelial area and MUC5AC and EGFR expression}

The total epithelial area was slightly decreased after treatment with fluticasone, although this did not reach statistical significance ( $\mathrm{p}=0.054$; fig. $3 \mathrm{a})$. As described previously [1], AB/PAS- and MUC5AC-stained areas were not different from one another in polyp epithelium (data not shown). MUC5AC staining was present in epithelial goblet cells, and the MUC5AC-stained area was unaffected by fluticasone ( $\mathrm{p}=0.91$ ) (fig. 3b). MUC5AC mRNA assessed by in situ hybridisation showed strong signals before and after steroid treatment (fig. 4). Hybridisation with a sense probe for MUC5AC mRNA showed no signal (data not shown).

EGFR-positive staining was present in all polyp specimens before and after treatment with fluticasone. Staining was found especially in basal cells but also in Clara cells (fig. 4). No staining for EGFR protein was found in mature mucincontaining (goblet) cells. Fluticasone had no significant effect on EGFR-stained area ( $\mathrm{p}=0.82$; fig. $3 \mathrm{c}$ ). When antibodies were omitted or when the staining procedure was performed with an irrelevant mouse $\mathrm{Ab}$, no staining was observed (data not shown).

\section{$I L-8$}

Staining for IL-8 was present in nasal polyp epithelium and was localised to basal and ciliated epithelial cells; however, IL-8 was not present in goblet cells. Some inflammatory cells infiltrating airway epithelium also expressed positive staining for IL-8. IL-8-stained area in epithelium was not affected by treatment with fluticasone $(\mathrm{p}=0.65$; fig. $5 \mathrm{a})$. No significant correlation was found between intra-epithelial neutrophils and IL-8 expression ( $\mathrm{r}=-0.051, \mathrm{p}=0.84, \mathrm{n}=18$ polyps, Spearman Rank correlation).
$T N F-\alpha$

TNF- $\alpha$-expressing cells were regularly found in polyp epithelium, mostly in inflammatory cells infiltrating polyp epithelium; epithelial cells also expressed TNF- $\alpha$. TNF- $\alpha$ positively stained cell numbers were not different before and after fluticasone treatment ( $\mathrm{p}=0.82$; fig. 5b).

\section{Discussion}

Corticosteroids are useful in therapy of nasal polyps, but their effects on mucin expression are not definitely established. In the present study, mucin synthesis was unaffected by corticosteroids. The lack of corticosteroid effect on mucin production could not be due to ineffective drug delivery, because the therapy decreased the polyp size (as manifested by a decrease in nasal airflow resistance) and decreased eosinophil infiltration, indicating that drug deposition was effective. The present study was designed with these positive controls, based on previous studies, which showed that reduction in polyp size and eosinophil infiltration are consistent findings with intranasal corticosteroid therapy [8-10, 17, 20].

Evaluation of the effects of corticosteroids on mucins in subjects with nasal polyps has not been reported, to our knowledge. In lower airway epithelium of asthmatic patients, available studies show conflicting data regarding effect of local steroids on goblet cell metaplasia and mucin expression. LAITINEN et al. [21] studied bronchial biopsies obtained before treatment and after 3 months of treatment with budesonide (600 $\mu \mathrm{g}$, twice daily) in seven asthmatic subjects. The authors reported significant increase in ciliated-to-goblet cell index after treatment with inhaled budesonide. However, no data were presented concerning mucin gene or protein expression. GRONEBERG et al. [22] reported no change in mucin content after a month of inhaled budesonide therapy, using a semiquantitative analysis of MUC5AC mucin staining of bronchial biopsies. FAHY et al. [23] reported that a month of inhaled beclomethasone therapy did not affect mucin-like glycoproteins in the sputum of moderate asthmatics. The present study is the first to assess effects of local steroids in human airway epithelium in vivo on both mucin gene and protein expression, using quantitative morphometric analysis. The data presented here show that mucin protein content in epithelium is
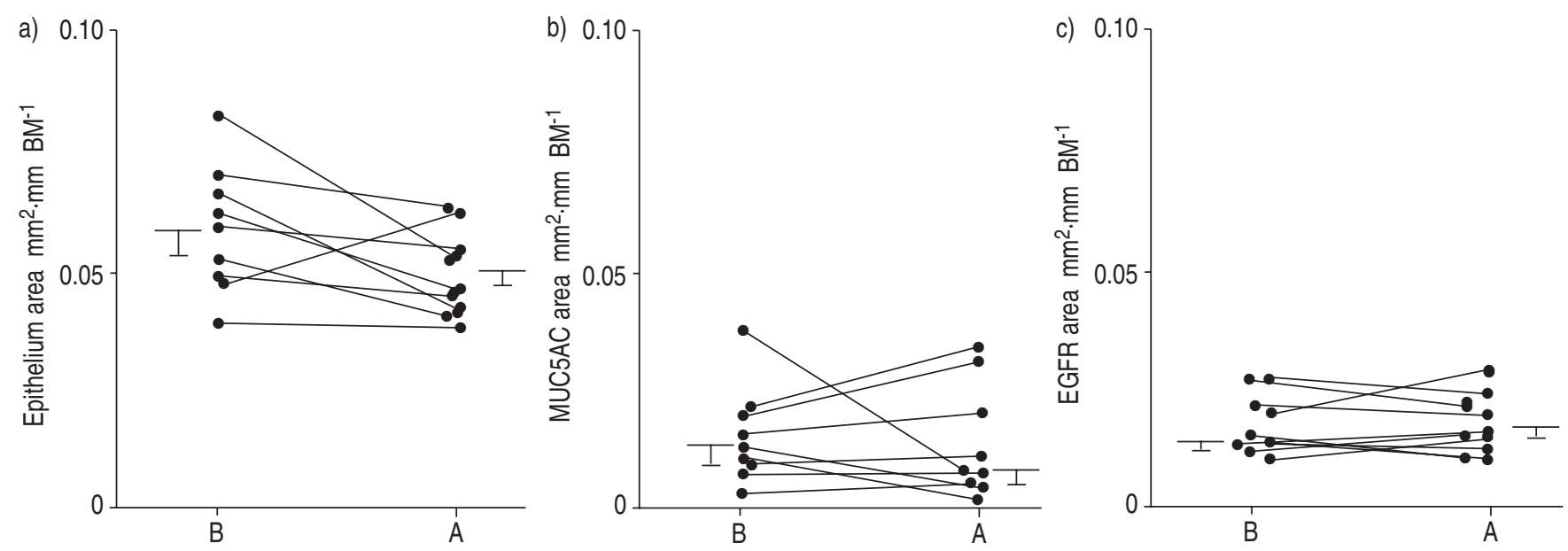

Fig. 3.-Data obtained from morphometric analysis of tissue sections stained with MUC5AC or epidermal growth factor receptor (EGFR) monoclonal antibodies in subjects before (B) and after (A) fluticasone treatment. Areas, measured by point-counting, were expressed in mm ${ }^{2}$ per $\mathrm{mm}$ of basal membrane (BM). A small, insignificant decrease in a) epithelial area was found after therapy ( $\mathrm{p}=0.054)$; no changes were found for b) MUC5AC- or c) EGFR-stained areas ( $\mathrm{p}=0.91$ and $\mathrm{p}=0.82$, respectively). Connecting lines indicate data obtained in the same subject. Horizontal bars represent median values. Vertical bars indicate SEM. 


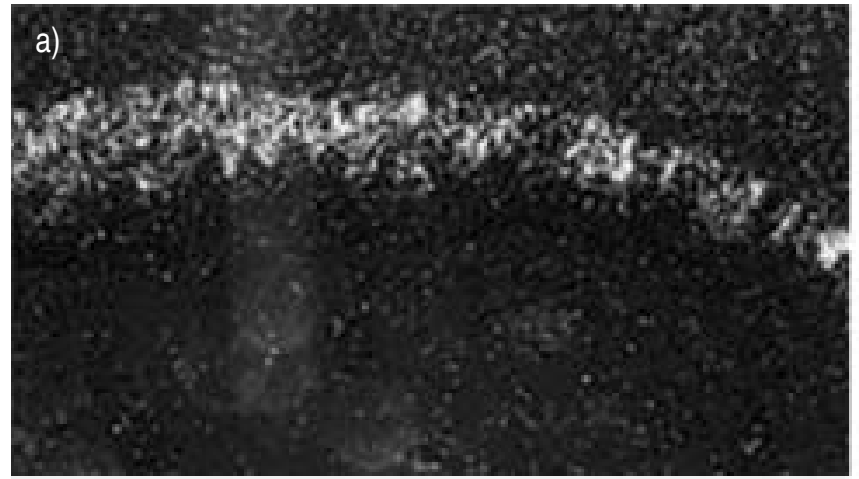

c)
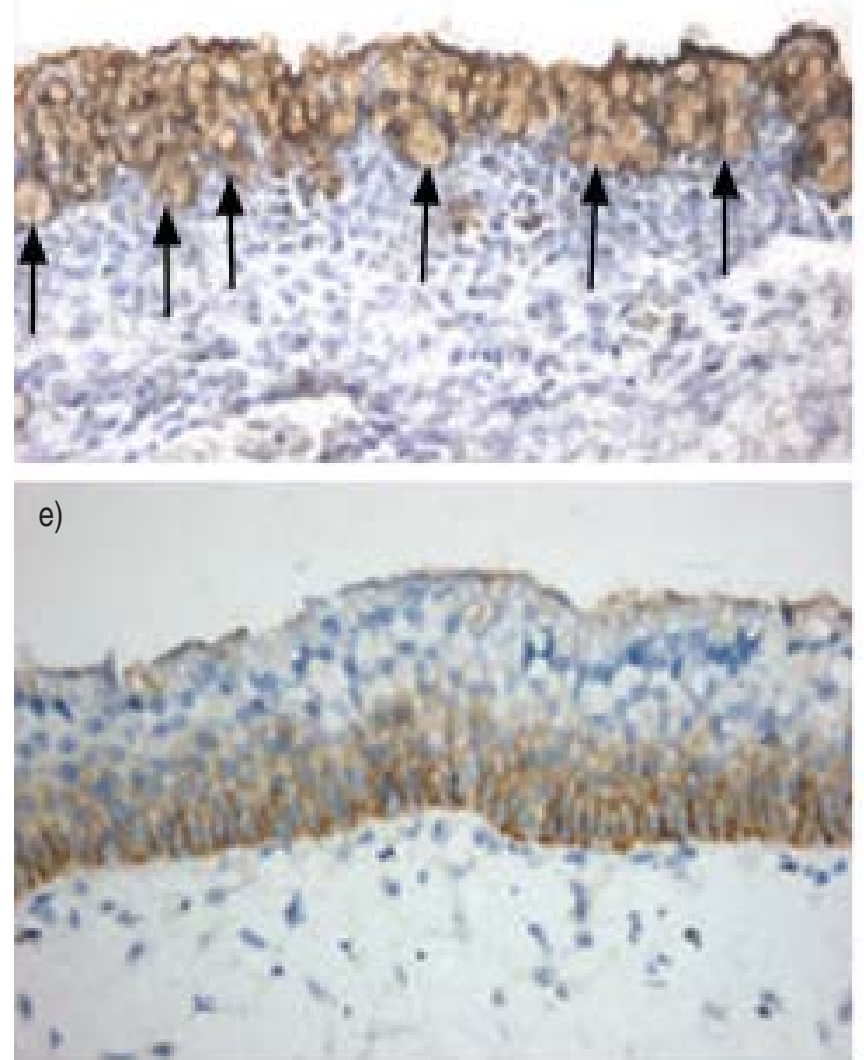

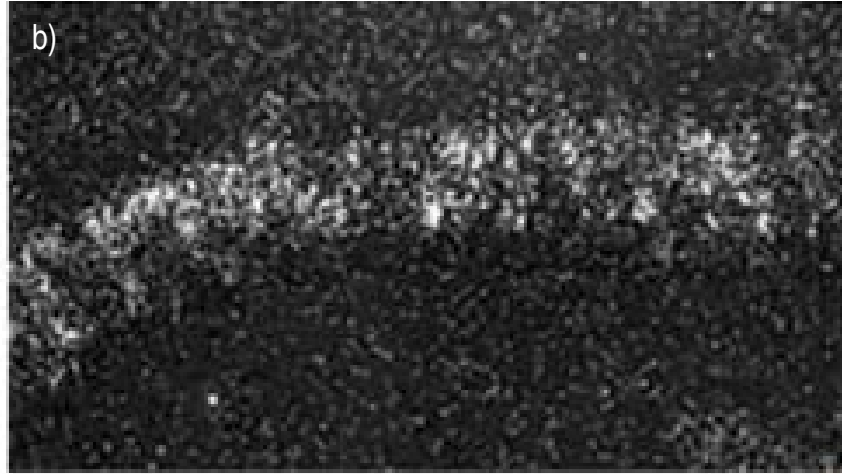

d)
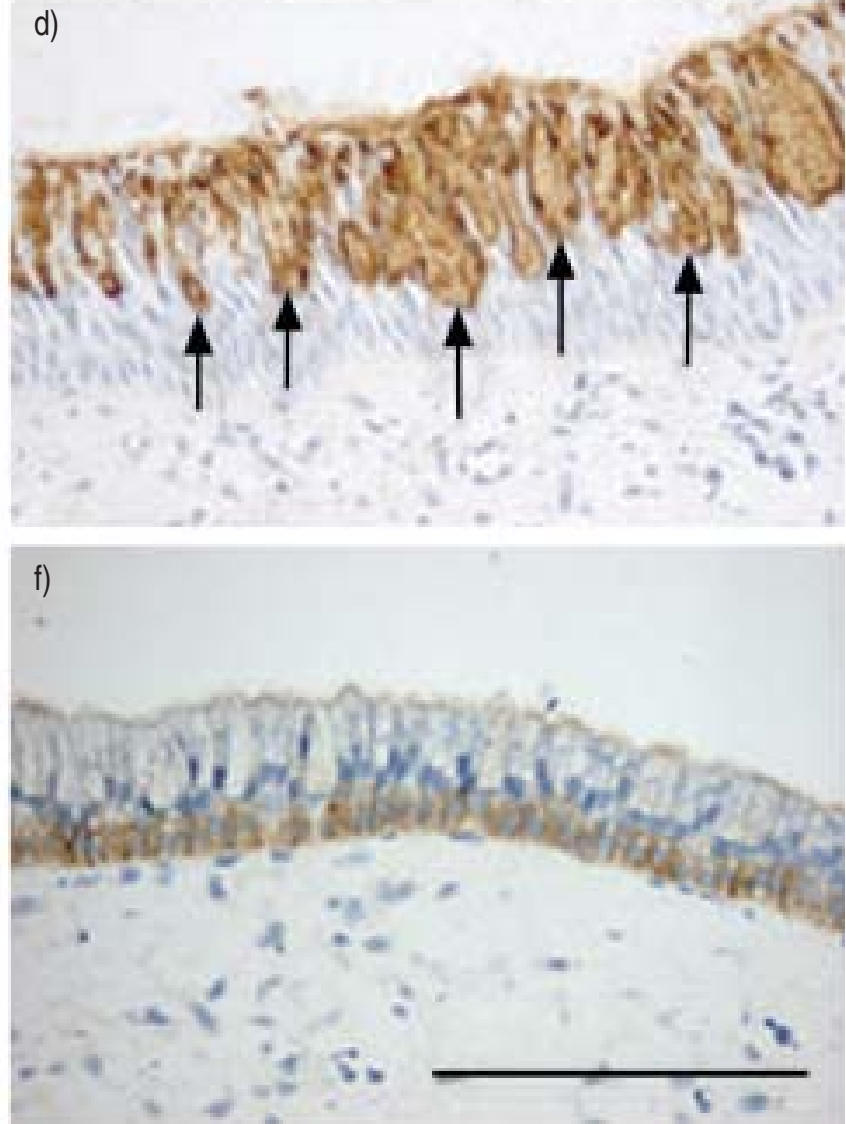

Fig. 4. - Representative photomicrographs of in situ hybridisation for MUC5AC mRNA (a and b), and immunolocalisation for MUC5AC protein (c and d) and epidermal growth factor receptor (EGFR) protein (e and f), before (a, c and e) and after (b, d, and f) steroid treatment. Before treatment, the in situ hybridisation signal for MUC5AC mRNA (seen as white dots under dark field) was strong in polyp epithelium; MUC5AC protein was localised to epithelial goblet cells (arrows). Staining for EGFR protein was present in basal and Clara cells, but not in mature mucus-containing (goblet) cells. After treatment with intranasal fluticasone no changes were observed in signals for MUC5AC mRNA, MUC5AC protein or EGFR protein. Images are representative of findings in nine subjects for immunolocalisation and in four subjects for in situ hybridisation. Scale bar $=50 \mu \mathrm{m}$.

unchanged by usual doses of intranasal steroids. The presence of mucus in airway epithelium is related to mucin synthesis (that increases mucin contents) and to mucin secretion (that decreases mucin contents). Therefore, the persistence of mucin protein expression in airway epithelium after treatment with intranasal steroids may be related to effects on mucin synthesis and/or mucin secretion. Importantly, using in situ hybridisation, it was found that MUC5AC gene expression is not abolished by therapy. This study design did not allow for studying mucin secretion. However, MACGREGOR et al. [24], measuring secreted mucous glycoproteins in nasal lavage fluid in normal subjects, concluded that intranasal steroids potentiate mucin secretion. Taken together, these results suggest that local steroids do not inhibit either mucin synthesis or mucin secretion and that alternative treatment is required to treat mucus hypersecretion.

No data are available regarding the magnitude of the reduction in mucin content that is clinically significant, so the number of subjects necessary to draw negative conclusions could not be determined. Therefore, the possibility that intranasal steroids have small effects on mucin expression cannot be ruled out and studies analysing larger numbers of subjects may show some positive effects.

A small decrease in total epithelial area was found after steroid treatment. Because intranasal steroids had no effect on mucin-producing cells, this finding could be related to effects of steroids on other epithelial cell types (e.g. ciliated cells, basal cells). 

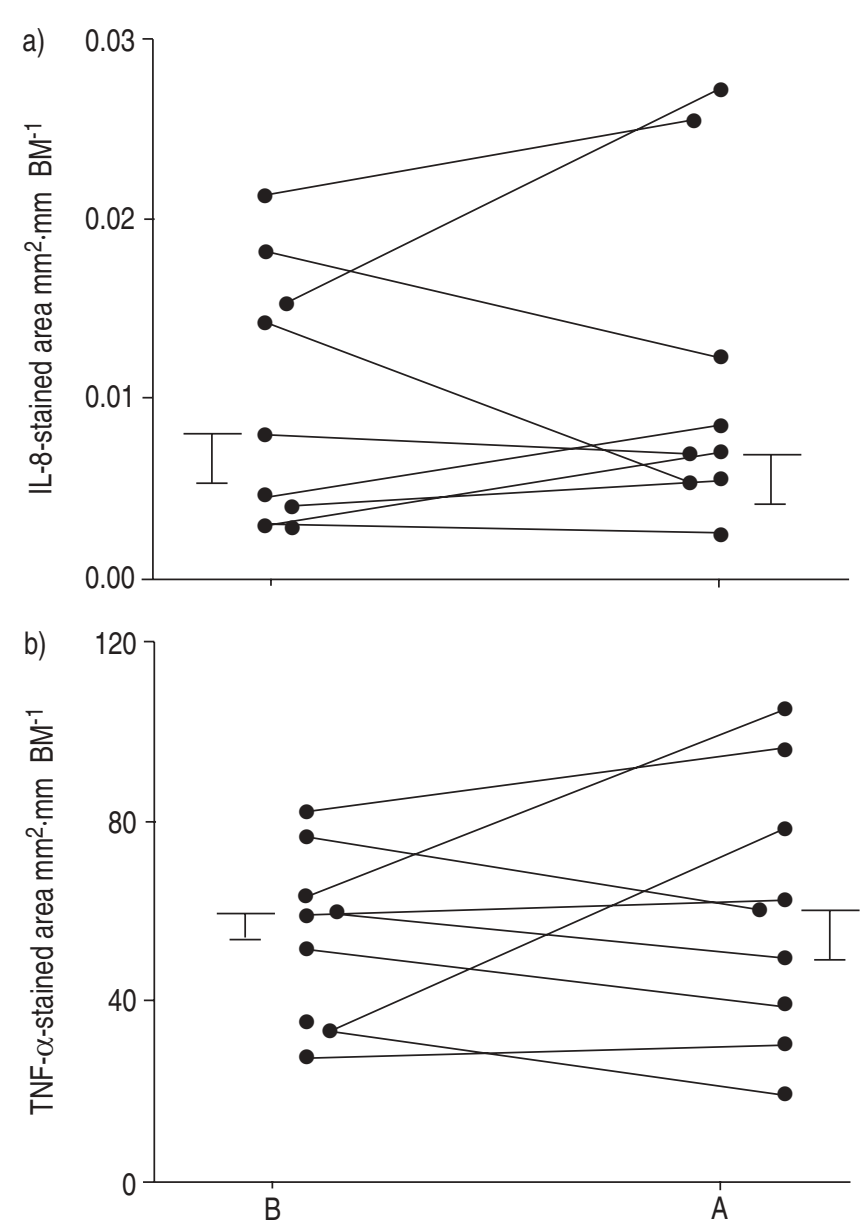

Fig. 5.-a) Interleukin (IL)-8-stained area and b) tumour necrosis factor (TNF)- $\alpha$-stained cells were counted in polyp epithelium of subjects before (B) and after (A) fluticasone treatment. Fluticasone had no significant effect on IL-8-stained area $(\mathrm{p}=0.65)$ or on TNF- $\alpha$ stained cells $(\mathrm{p}=0.82)$. Connecting lines indicate data obtained in the same subject. Horizontal bars represent median values. Vertical bars indicate SEM.

EGFR expression and activation have been shown to be involved in mucin production in human airway epithelial cells and in animal models by various molecules, by allergen [14] and by a wide variety of other stimuli [25]. The association between EGFR and mucin expression suggests the possibility that an EGFR cascade is responsible for mucin production in polyps [1]. Here it is shown that neither EGFR nor mucin expression is affected by intranasal corticosteroid therapy. These results are in agreement with the reported lack of effect of inhaled corticosteroids on EGFR expression in asthmatic airway epithelium [27]. TNF- $\alpha$ has been shown to induce EGFR expression in airways [14]. TNF- $\alpha$ is absent from normal nasal tissues but is expressed in nasal polyps $[1,28]$. In this study, the presence of TNF- $\alpha$ in polyp epithelium, mostly in infiltrating inflammatory cells, has been confirmed. Interestingly, both TNF- $\alpha$ and EGFR expression were unaffected by intranasal corticosteroids.

Neutrophils and eosinophils are prominent in airways of patients with various hypersecretory diseases, suggesting roles for these cells in mucin synthesis [29]. Studies conducted in animals have shown conflicting data regarding roles of eosinophils in goblet cell metaplasia and mucin synthesis. Using IL-5-deficient mice, CoHN et al. [30] showed that Thelper 2-induced airway mucus production is independent of eosinophils. However, SHEN et al. [31] reported that transfer of eosinophils in IL-5-deficient mice restored mucous cell metaplasia in response to ovalbumin challenge. In the present study, inhibition of eosinophil infiltration by intranasal steroids was not associated with a reduction in mucin gene and protein expression, suggesting that mucin synthesis can occur in the absence of eosinophils in polyps. Neutrophil infiltration was unaffected by steroid treatment and could contribute to mucin production.

It was found in this study that nasal polyp epithelium expresses IL-8, a potent neutrophil chemoattractant, confirming a previous report that IL-8 expression is increased in polyps compared to healthy nasal mucosa [4]. The persistence of IL-8 and neutrophils after fluticasone therapy is compatible with the hypothesis that IL-8 is responsible, at least in part, for neutrophil recruitment in nasal polyp epithelium. A correlation was not found between intra-epithelial neutrophils and IL-8 expression. However, because neutrophil transmigration in airway epithelium is rapid and because IL-8 expressed in epithelial cells leaves the cells rapidly, a correlation between IL-8 expression and intra-epithelial neutrophils would not necessarily be expected.

In conclusion, treatment with intranasal fluticasone was effective in reducing polyp size and in suppressing eosinophil infiltration. However, this treatment did not affect mucin production, epidermal growth factor receptor expression or neutrophil infiltration. It is suggested that selective inhibitors of epidermal growth factor receptor tyrosine phosphorylation or inhibition of selected neutrophil products could be useful in inhibiting mucus overproduction in nasal polyps and in other hypersecretory diseases. Furthermore, because of their location and accessibility, nasal polyps provide a convenient "model" for evaluating various therapies in the suppression of mucin production in the respiratory system. Appropriate clinical studies are needed to evaluate these therapeutic possibilities.

Acknowledgements. The authors would like to acknowledge D.C.W. Tam for technical assistance.

\section{References}

1. Burgel PR, Escudier E, Coste A, et al. Relation of epidermal growth factor receptor expression to goblet cell hyperplasia in nasal polyps. J Allergy Clin Immunol 2000; 106: 705-712.

2. Demoly P, Sahla M, Campbell AM, Bousquet J, Crampette L. ICAM-1 expression in upper respiratory mucosa is differentially related to eosinophil and neutrophil inflammation according to the allergic status. Clin Exp Allergy 1998; 28: 731-738.

3. Nocker RE, Schoonbrood DF, van de Graaf EA, et al. Interleukin-8 in airway inflammation in patients with asthma and chronic obstructive pulmonary disease. Int Arch Allergy Immunol 1996; 109: 183-191.

4. Allen JS, Eisma R, Leonard G, Lafreniere D, Kreutzer D. Interleukin-8 expression in human nasal polyps. Otolaryngol Head Neck Surg 1997; 117: 535-541.

5. Takeyama K, Dabbagh K, Shim JJ, Dao-Pick T, Ueki IF, Nadel JA. Oxidative stress causes mucin synthesis via transactivation of epidermal growth factor receptor: role of neutrophils. J Immunol 2000; 164: 1546-1552.

6. Kohri K, Ueki IF, Nadel JA. Neutrophil elastase induces mucin production by ligand-dependent epidermal growth factor receptor activation. Am J Physiol Lung Cell Mol Physiol 2002; 283: L531-L540.

7. Burgel PR, Lazarus SC, Tam DC, et al. Human eosinophils induce mucin production in airway epithelial cells via epidermal growth factor receptor activation. J Immunol 2001; 167: 5948-5954.

8. Keith P, Nieminen J, Hollingworth K, Dolovich J. Efficacy 
and tolerability of fluticasone propionate nasal drops 400 microgram once daily compared with placebo for the treatment of bilateral polyposis in adults. Clin Exp Allergy 2000; 30: 1460-1468.

9. Penttila M, Poulsen P, Hollingworth K, Holmstrom M. Dose-related efficacy and tolerability of fluticasone propionate nasal drops $400 \mathrm{mg}$ once daily and twice daily in the treatment of bilateral nasal polyposis: a placebo-controlled randomized study in adult patients. Clin Exp Allergy 2000; 30: 94-102.

10. Hamilos DL, Thawley SE, Kramper MA, Kamil A, Hamid QA. Effect of intranasal fluticasone on cellular infiltration, endothelial adhesion molecule expression, and proinflammatory cytokine mRNA in nasal polyp disease. J Allergy Clin Immunol 1999; 103: 79-87.

11. Ordonez CL, Khashayar R, Wong HH, et al. Mild and moderate asthma is associated with airway goblet cell metaplasia and abnormalities in mucin gene expression. Am J Respir Crit Care Med 2001; 163: 517-523.

12. Davies JR, Svitacheva N, Lannefors L, Kornfalt R, Carlstedt I. Identification of MUC5B, MUC5AC and small amounts of MUC2 mucins in cystic fibrosis airway secretions. Biochem J 1999; 344: 321-330.

13. Groneberg DA, Peiser C, Dinh T, et al. Distribution of respiratory mucin proteins in human nasal mucosa. Laryngoscope 2003; 113: 520-524.

14. Takeyama K, Dabbagh K, Lee HM, et al. Epidermal growth factor system regulates mucin production in airways. Proc Natl Acad Sci USA 1999; 96: 3081-3086.

15. Park HS, Kim HY, Nahm DH, Park K, Suh KS, Yim H. The presence of atopy does not determine the type of cellular infiltrate in nasal polyps. Allergy Asthma Proc 1998; 19: 373377.

16. Lund VJ, Flood J, Sykes AP, Richards DH. Effect of fluticasone in severe polyposis. Arch Otolaryngol Head Neck Surg 1998; 124: 513-518.

17. Mastruzzo C, Greco LC, Nakano K, et al. Impact of intranasal budesonide on immune inflammatory responses and epithelial remodeling in chronic upper airway inflammation. J Allergy Clin Immunol 2003; 112: 37-44.

18. Malm L, Gerth van Wijk R, Bachert C. Guidelines for nasal provocations with aspects on nasal patency, airflow, and airflow resistance. Rhinology 2000; 38: 1-6.

19. Lou YP, Takeyama K, Grattan KM, et al. Platelet-activating factor induces goblet cell hyperplasia and mucin gene expression in airways. Am J Respir Crit Care Med 1998; 157: $1927-1934$.

20. Mygind N, Nielsen LP, Hoffmann HJ, et al. Mode of action of intranasal corticosteroids. J Allergy Clin Immunol 2001; 108: S16-S25.

21. Laitinen LA, Laitinen A, Haahtela T. A comparative study of the effects of an inhaled corticosteroid, budesonide, and a beta 2 -agonist, terbutaline, on airway inflammation in newly diagnosed asthma: a randomized, double-blind, parallelgroup controlled trial. J Allergy Clin Immunol 1992; 90: 3242.

22. Groneberg DA, Eynott PR, Lim S, et al. Expression of respiratory mucins in fatal status asthmaticus and mild asthma. Histopathology 2002; 40: 367-373.

23. Fahy JV, Boushey HA. Effect of low-dose beclomethasone dipropionate on asthma control and airway inflammation. Eur Respir J 1998; 11: 1240-1247.

24. MacGregor FB, Robson AG, Pride NB. Topical corticosteroids potentiate mucin secretion in the normal nose. Clin Otolaryngol 1996; 21: 76-79.

25. Nadel JA, Burgel PR. The role of epidermal growth factor in mucus production. Curr Opin Pharmacol 2001; 1: 254 258.

26. Takeyama K, Fahy JV, Nadel JA. Relationship of epidermal growth factor receptors to airway goblet cell production. Am J Respir Crit Care Med 2001; 163: 511-516.

27. Puddicombe SM, Polosa R, Richter A, et al. Involvement of the epidermal growth factor receptor in epithelial repair in asthma. FASEB J. 2000; 14: 1362-1374.

28. Hamilos DL, Leung DY, Wood R, et al. Eosinophil infiltration in nonallergic chronic hyperplastic sinusitis with nasal polyposis (CHS/NP) is associated with endothelial VCAM-1 upregulation and expression of TNF-alpha. $A m$ J Respir Cell Mol Biol 1996; 15: 443-450.

29. Burgel PR, Nadel JA. Mucus and mucin-secreting cells. In: Barnes P, Drazen J, Rennard S, Thomson N, eds. Asthma and COPD. London, Academic Press, 2002; pp. 155-163.

30. Cohn L, Homer RJ, MacLeod H, Mohrs M, Brombacher F, Bottomly K. Th2-induced airway mucus production is dependent on IL-4Ra, but not on eosinophils. J Immunol 1999; 162: 6178-6183.

31. Shen HH, Ochkur SI, McGarry MP, et al. A causative relationship exists between eosinophils and the development of allergic pulmonary pathologies in the mouse. $J$ Immunol 2003; 170: 3296-3305. 